\title{
Research on Transformer Winding Fault Detection Method Based on the Voltage and Current Characteristics of LISSAJOUS
}

\author{
Hui Xu', Guanchen Lu' ${ }^{\mathrm{b}}$, Zhangqi Wang ${ }^{\mathrm{c}}$ \\ Mechanical Engineering, North China Electric Power \\ University, Baoding, China \\ axuhui2132224047@163.com, b417030221@qq.com, \\ c568340721@qq.com
}

\author{
Hong Yu ${ }^{\mathrm{d}}$, Guochao Qian ${ }^{\mathrm{e}}$ \\ Institute of High Pressure, Yunnan Power Grid Electric \\ Power Research Institute Co., Ltd, Kunming, China \\ dyuhong2388245@163.com, ${ }^{\mathrm{e}} 13698707646 @ 139 . c o m$
}

\author{
Zhongxi Lu \\ Power Engineering, North China Electric Power University, Baoding, China \\ 378288023@qq.com
}

\begin{abstract}
Transformer power system is one of the most important electrical equipment, winding transformer failure is an important cause of damage and threaten the safe operation of the power grid. Through theoretical analysis, we propose a Lissajous analysis of transformer voltage / current characteristic analysis method to detect winding faults, while the design of the experimental method, by specific experiments further confirmed Lissajous characteristic analysis method based on effectiveness of transformer winding faults provides a new detection method.
\end{abstract}

Keywords-transformer; transformer winding; interpolation; Lissajous

\section{INTRODUCTION}

Transformer winding state operating conditions and factors, such as insulation and historical data have a complex relationship, existing research is mainly on the winding fault fixed operating environment equivalent model test analysis and simulation of the winding, due to the lack of measured data lack of support, often makes the analysis necessary to verify the validity of the results, limiting the study in response to changes in the mechanism of winding failure. ${ }^{[3]}$ Lissajous figure method can find an online monitoring and identification methods, effective access to the response characteristics of the transformer winding, will promote the improvement of transformer winding fault diagnosis technology. ${ }^{[7]}$

\section{LISSAJOUS FIGURES ANALYSIS FUNDAMENTALS}

For analysis of the short-circuit impedance method parameters characteristic less, and can not find fault capacitive faults proposed structure transformer voltage and current Lissajous figures, winding deformation analysis method, a new method to establish an on-line monitoring of winding deformation.

Transformers line input voltage, input current with the same frequency, by eliminating the common time parameter $t$, you can get the input voltage and input current relationship building between the two Lissajous figures. Set the input voltage to y1 said its amplitude to A1 represents the input current to y2 said its amplitude to A2, said initial phase $\varphi$, said time $t$ indicated by the angular frequency $\omega$, said the relationship between the two derived as follows:

$$
\begin{aligned}
& y_{1}=A_{1} \cos (\omega t) \\
& y_{2}=A_{2} \cos (\omega t+\varphi)
\end{aligned}
$$

Through the triangular transformation, the equation (2) can be transformed as Equation (3):

$$
y_{2}=A_{2}[\cos (\omega t) \cos \varphi-\sin (\omega t) \sin \varphi]
$$

$$
\cos ^{2}(\omega t)+\sin ^{2}(\omega t)=1
$$

According to equation (4), the equation (1) into Equation (3), can be obtained equation (5):

$$
\frac{y_{1}^{2}}{A_{1}^{2}}+\frac{y_{2}^{2}}{A_{2}^{2}}-2 \frac{y_{1} y_{2}}{A_{1} A_{2}} \cos \varphi-\sin ^{2} \varphi=0
$$

Let

$$
A=\frac{1}{A_{1}^{2}}, B=\frac{2 \cos \varphi}{A_{1} A_{2}}, C=\frac{1}{A_{2}^{2}}, D=-\sin ^{2} \varphi
$$

Then

$$
B^{2}-4 A C=\frac{4}{A_{1}^{2} A_{2}^{2}}\left(\cos ^{2} \varphi-1\right) \leq 0
$$

When the value of the formula (7) is less than $0, y 1, y 2$ configured elliptical pattern (Lissajous). 
Voltage from the transformer, the current configuration of the vector diagram (Fig.1b) can be seen, the primary side of the transformer can not issue a power, voltage, phase current does not reach $180^{\circ}$. So for the transformer, the formula (1.7) the result would be less than zero, that is, its voltage and current will constitute Lissajous oval pattern shown in Fig.2.

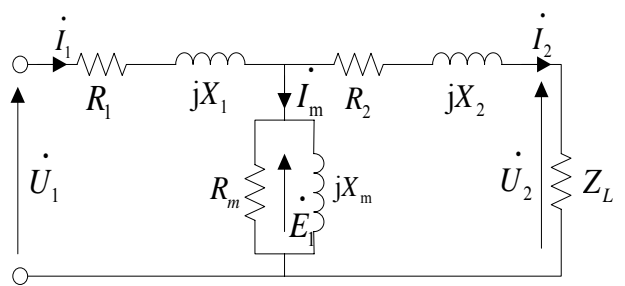

(a) Equivalent circuit voltage transformer

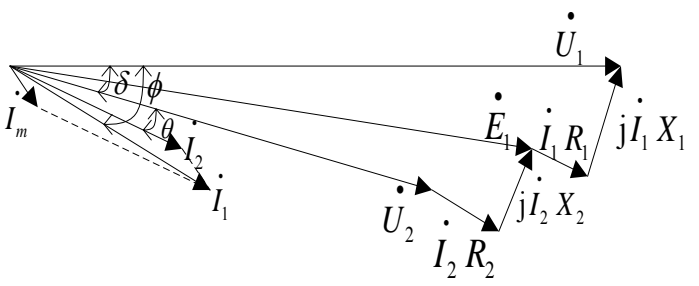

(b) The transformer voltage, current vector diagram

Figure 1. Transformer voltage, current relationship diagram

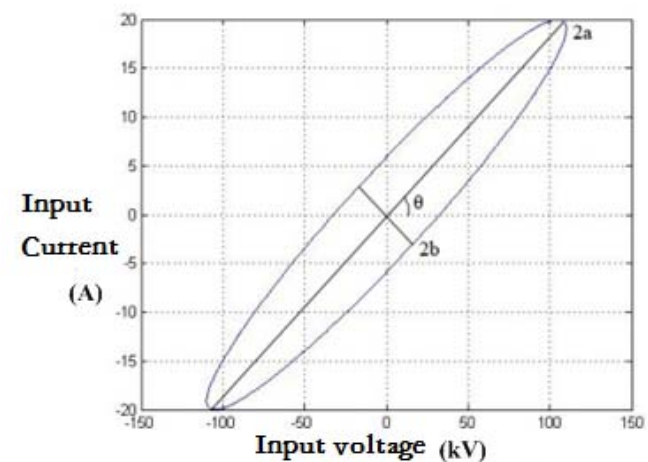

Figure 2. Lissajous transformer voltage, current composition

Where, $k=\tan \theta, \quad e=\sqrt{1-\frac{b^{2}}{a^{2}}}$ 。

Therefore, by the Lissajous ellipse pattern (Fig.2) of the major axis (a), the minor axis (b), the slope (k), eccentricity (e) other parameters analyzed transformer equivalent circuit parameters change. Because Lissajous figures capable of analyzing the response characteristics of the transformer winding, which can reflect both changes in the equivalent inductance winding, winding can also reflect the equivalent resistance and capacitance changes to improve the reliability and validity of judgments winding deformation.
Considering the transformer during operation, the load is always changing. Although in a series of measures to protect and stable operation of the power grid, the nature and size of the load within a certain time a small change, but it will still be directly change the transformer equivalent circuit parameters, thereby changing its response, causing the voltage and current composition Lissajous such as changes in the graphic. When the over-voltage or short circuit fault is removed, the transformer can still run short in normal conditions, but the load is changed greatly. Therefore, it must be real-time monitoring of load characteristic, Lissajous graphics features to consider changes caused by load changes, the impact of changes and amendments to the load, thus avoiding the introduction of winding deformation load variation diagnostic errors.

In addition, there is a transformer magnetic material makes its operation may have a non-linear characteristics. However, conventional transformer saturation magnetic flux permeable material is between 1.15 to 1.4 times the rated magnetic flux, and under normal operating conditions, the transformer is in the linear region of magnetic material, the magnetic flux which does not exceed 1.1 times the rated flux. When a short circuit or over-voltage fault is eliminated, the transformer can be short running under normal operating conditions.

In summary, both before and after the failure of transformer has a linear characteristic, therefore, may be a phase winding transformer is equivalent to a linear two-port network, consider the impact of real-time load variation, amendment Lissajous method. As shown in Fig.3, an equivalent circuit diagram for the transformer when a load ZL.

As shown in Fig.4(a), when transformer load changing from $Z_{L}$ to $Z_{L}^{\prime}$, the input voltage $\dot{U}_{1}$,input current $\dot{I}_{1}$, output voltage $^{\dot{U}_{2}}$, output current $\dot{I}_{2}$, respectively become ${\dot{U_{1}^{\prime}}}^{\prime}, \dot{I_{1}^{\prime}}, \dot{U_{2}^{\prime}}, \dot{I}_{2}^{\prime}$. According to the circuit schematic, the circuit can be equivalent to Fig.4 (b). According to the linear network with a superposition and electrical network reciprocity theorem $\dot{U}_{1}, \dot{U}_{1 d}, \dot{U}_{2 d}$ can be obtained on the secondary side of the current response are shown in equation (8), (9), (10), the source of the three common response satisfies (11) as shown in the equation. By the equation (11) can be of different load normalization processing, the response to different loads are converted in response to the load $Z_{L}$, thus avoiding the effect of load changes.

$$
\begin{gathered}
\dot{U}_{1} \rightarrow \dot{U}_{2} \\
\dot{U_{1 d}} \rightarrow \dot{I}_{2} \frac{\dot{U_{1 d}}}{\dot{U}_{1}}
\end{gathered}
$$




$$
\dot{U_{2 d}} \rightarrow \dot{I_{2}} \frac{K \dot{U_{2 d}}}{\dot{U}_{1}}
$$

$$
\dot{I_{2}^{\prime}}=\dot{I}_{2}+\dot{I}_{2} \frac{\dot{U_{1 d}}}{\dot{U}_{1}}-\dot{I_{2}} \frac{K \dot{U_{2 d}}}{\dot{U}_{1}}
$$

$$
\text { Where } K=\frac{\dot{I_{2}^{\prime}}}{\dot{I_{1}^{\prime}}} \text {. }
$$

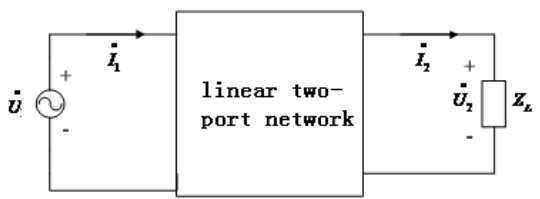

Figure 3. Transformer equivalent linear two-port network

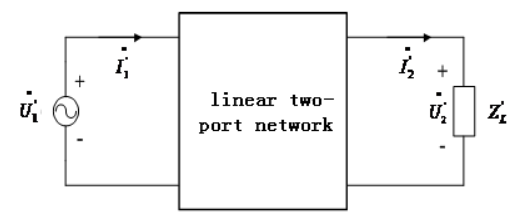

(a) After a two-port network transformer load changes

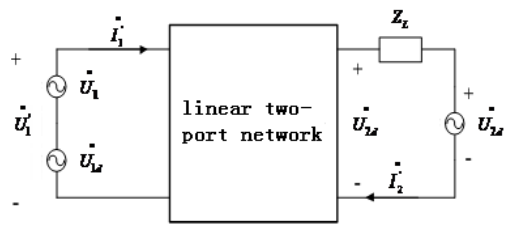

(b) The load change transformer equivalent two-port network

Figure 4. Load transformer equivalent two-port network changes

\section{EXPERIMENTAL PLATFORM AND RESULT ANALYSIS}

In order to verify the validity and sensitivity Lissajous figure method to determine and analyze the winding deformation, a maintenance base in Chongqing to build a transformer winding test platform. Select the fault in the transformer winding deformation demolition carried out test winding winding winding case covers health, spoke to the deformation of the winding, winding axis offset, pitch change between cake winding, winding inter-turn short circuit, etc., winding through different tests Research Lissajous figure parameter variation with winding real deformation failure. Select fault transformer manufacturers are the same.

Test for $220 \mathrm{~V}$ power frequency voltage source, the test load is $50 \Omega$ power resistors, the test voltage measuring device for Tektronix P5100A probes, test current measurement device for Pearson 101 coils for Tektronix Digital Phosphor Oscilloscopes Oscilloscopes DPO4054, test cables were for copper, coaxial cable and high-voltage wire. Test using $220 \mathrm{~V}$ power frequency test, winding and $50 \Omega$ power resistor in series with the main test circuit. In order to avoid error wiring and wiring length introduced, all wiring and wire and cable test model uses exactly the same, the specific connection shown in Fig.5. Respectively, the input voltage and output current probe coil and Pearson measured and displayed with an oscilloscope and data acquisition.

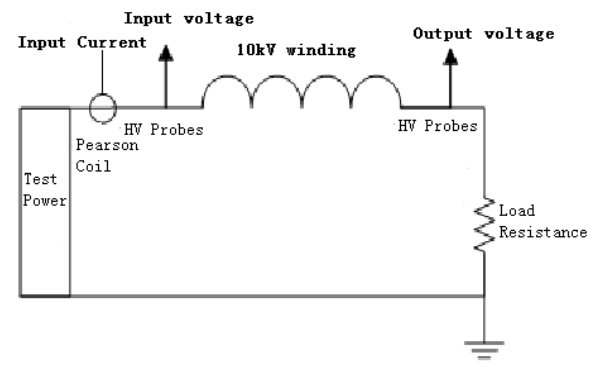

Figure 5. Schematic test

Lissajous graphical analysis method uses fundamental analysis Frequency winding state, you need to extract the fundamental component of the measurement signal through the FFT algorithm. In order to reduce the influence of external disturbances and brought discrete waveform, white noise and eliminate interference, the fundamental component for obtaining the averaging processing; To eliminate the influence of input voltage fluctuations at different winding test, the fundamental wave at the different winding test voltage component to build unified into $500 \mathrm{~V}$ Lissajous figure, and accordingly a current signal conversion processing, and extracts a feature quantity Lissajous figure of comparison and analysis. Data processing flow shown in Fig.6.

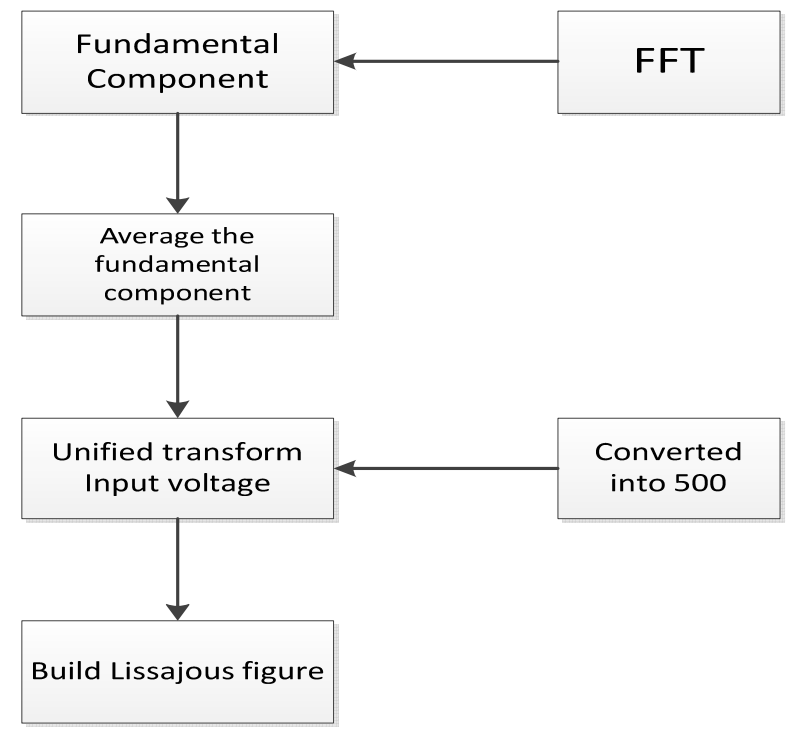

Figure 6. Data processing flow chart 
In order to facilitate the analysis and highlight the differences winding input voltage and output current constitution of Lissajous figures, expressed in the same figure Lissajous five winding, as shown in Fig.7.

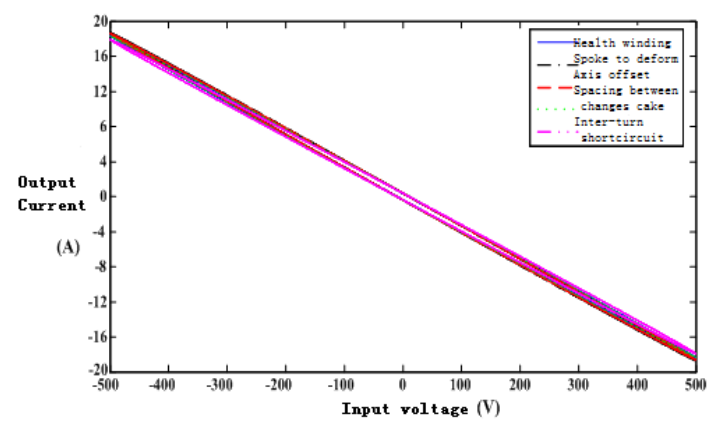

(a)Lissajous figures of different winding

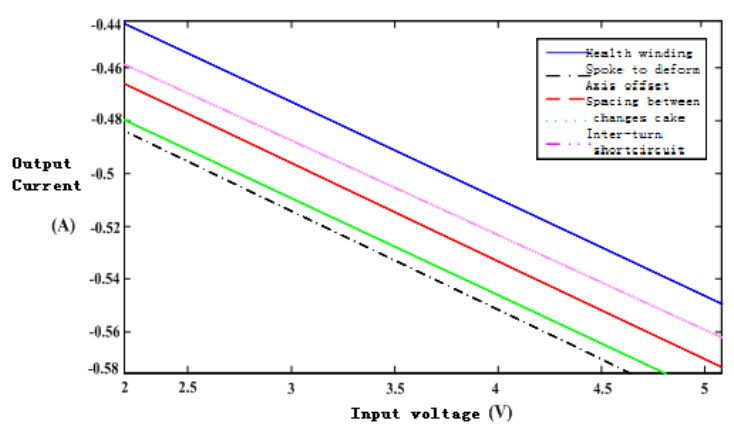

(b) Lissajous enlarged contrast 1

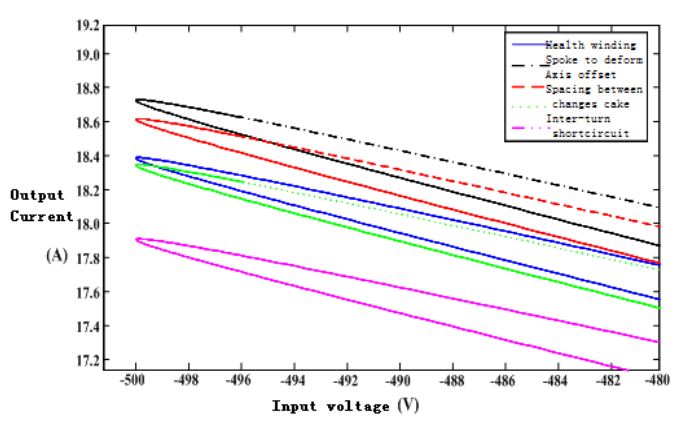

(c) Lissajous enlarged contrast 2

Figure 7. Different winding input voltage and output current composition Lissajous

\section{SUMMARY}

According to the equivalent circuit winding when winding deformation, the equivalent circuit parameters will change its Lissajous response characteristics corresponding changes will occur. Because different winding deformation, the equivalent circuit parameters change is not the same, and ultimately the formation of Lissajous figures are different. Fig.7, Lissajous health winding and winding various fault exists obvious differences. Fig.7 (b), each winding Lissajous figures do not coincide with each other in the minor axis of the ellipse, that is, its minor axis length varies; Fig.7 (c), each winding Lissajous figures in the long axis of the ellipse do not overlap each other, i.e., the major axis and the slope are different. Fig.7 intuitive performance and fault healthy winding winding Lissajous have obvious differences, but with different faults, Lissajous winding vary its parameters vary, which effectively verified Lissajous graphics can distinguish different deformation fault winding.

\section{ACKNOWLEDGMENT}

Thanks to the strong support of Yunnan Power Grid Co. For the simulation experiments. Thanks to the meticulous help which mentors and leaders gives. I will continue to work harder and strive for greater progress.

\section{REFERENCES}

[1] Li X, Gong Q W, Xiao H, etal. Positioning Based Distribution Network Fault Correlation matching degree [J]. Automation of Electric Power Systems. 2012 (01), pp. 90-95.

[2] Guo C X, Zhu C Z ,Zhang L, etal. Transformer Fault Diagnosis Using Multiple classification multicore support vector machine learning [J]. China Electrical Engineering 2010 (13), pp. 128-134.

[3] Yang T F, Li J L, Zeng X J, etal. Diagnosis based on a combination of large-scale multi-method transformer fault diagnosis model[J]. Automation of Electric Power System 2009 (20), pp. 92-95.

[4] Deng A D, Bao Y Q, Zhao L, etal. Rubbing Rotor acoustic emission source location of generalized cross-correlation time delay estimation [J]. China Electrical Engineering 2009 (14), pp. 86-92.

[5] Yan Q R, Liu X, Yin J G . Power transformer vibration signal wavelet theory research [J]. High Voltage Engineering. 2007 (01), pp. 165168.

[6] JI S C, Li Y M, Fu C Z. Load current method based on vibration signal analysis method to monitor the status of the transformer core application [J]. China Electrical Engineering 2003 (06), pp. 154-158.

[7] Wang Z Q, Wang M. Power transformer winding axial vibration stability analysis, [J]. China Electrical Engineering 2002 (07), pp. 2428. 